\title{
1 Interplay between bond breaking and plasticity during fracture at a 2 nanomolecularly-modified metal-ceramic interface
}

3 Matthew Kwan ${ }^{1}$, Muriel Braccini ${ }^{1,2}$, Ashutosh Jain ${ }^{1}$, Michael W. Lane ${ }^{3}$, and Ganpati Ramanath ${ }^{1 *}$ 4

$5 \quad{ }^{1}$ Rensselaer Polytechnic Institute, Materials Science \& Engineering Dept., Troy, NY, 12180, USA.

$6 \quad{ }^{2}$ CNRS, Laboratoire Science et Ingénierie des Matériaux et Procédés (SIMAP), F-38000 Grenoble, 7 France.

$8{ }^{3}$ Emory and Henry College, Chemistry Department, Emory, VA 24327, USA.

$9 \quad$ "E-mail: Ramanath@ rpi.edu

10

11 Abstract

12 We reveal the roles of moisture and temperature on the interplay between interfacial work of adhesion

$13 \gamma_{\mathrm{a}}$ and metal plasticity $\gamma_{\mathrm{p}}$ for a copper-silica interface modified with an organosilane nanolayer. We find

14 that $\gamma_{\mathrm{p}} \neq 0$ for interfaces with metal thicknesses $\mathrm{h}_{\mathrm{Cu}}>12 \mathrm{~nm}$, and increases with $\mathrm{h}_{\mathrm{Cu}}$ before it saturates at

$15 \mathrm{~h}_{\mathrm{Cu}} \sim 165 \mathrm{~nm}$. For a fixed $\mathrm{h}_{\mathrm{Cu}}, \gamma_{\mathrm{p}}$ increases due to temperature-induced yield stress decrease despite a 16 decrease in $\gamma_{a}$ with temperature because of water-induced siloxane bond weakening. These findings

17 should be valuable for understanding the fracture mechanics of, and designing, nanomolecularly-

18 functionalized interfaces subject to thermomechanical and chemical stresses.

19

20 Key Words: fracture, plasticity, interfaces, self-assembly, organosilane 
The thermo-mechanical and chemical integrity of interfaces[1-4] often determines the functionality, reliability, and performance of many materials systems such as composites and thin film devices. The interfacial fracture energy $\Gamma_{\mathrm{FT}}$ is typically comprised of contributions from multiple processes such as

4 bond-breaking[5] and crack-tip plastic energy dissipation.[6,7] Partitioning $\Gamma_{\mathrm{FT}}$ into the bond-breaking

5 work of adhesion $\gamma_{\mathrm{a}}$ and plastic energy dissipation $\gamma_{\mathrm{p}}$, e.g., as described by the Griffith-Irwin model,[5,6]

6 is key to understanding atomistic fracture mechanisms in terms of the interface chemistry. However,

7 experimentally partitioning $\Gamma_{\mathrm{FT}}$ is a challenge due to crack path uncertainties even for model

8 heterointerfaces where plasticity is confined to only one material[8]. Recently we showed a new 9 approach[9] to partition $\Gamma_{\mathrm{FT}}$ for a nanomolecularly-modified metal-ceramic interface. Copper-silica 10 interfaces treated with a nanomolecular monolayer (NML) of a mercaptan-terminated organosilane are 11 known to toughen due to $\mathrm{Cu}-\mathrm{S}$ bonding and thermally-activated siloxane ( $\mathrm{Si}-\mathrm{O}-\mathrm{Si}$ ) bridging[10]. 12 Introducing organosilane NMLs at metal-silica interfaces can obviate crack path uncertainties because 13 interfacial fracture occurs due to the scission of water-sensitive siloxane bridges [9-11]. Thus varying the 14 water partial pressure $\mathrm{p}_{\mathrm{H}_{2} \mathrm{O}}$ provides a means for adjusting $\gamma_{\mathrm{a}}$ through siloxane hydrolysis, and deducing $\gamma_{\mathrm{p}}$ 15 by subtracting $\gamma_{\mathrm{a}}$ from $\Gamma_{\mathrm{FT}}$. Further, $\gamma_{\mathrm{p}}$ is varied by changing the film thickness $\mathrm{h}_{\mathrm{Cu}}$ and temperature.

16 Here, we describe the effects of $\mathrm{p}_{\mathrm{H}_{2} \mathrm{O}}$, metal thickness $\mathrm{h}_{\mathrm{Cu}}$, and temperature, on the contributions of $\gamma_{\mathrm{a}}$ 17 and $\gamma_{\mathrm{p}}$ to $\Gamma_{\mathrm{FT}}$ for a model Cu/NML/silica interface. Partitioning $\Gamma_{\mathrm{FT}}$ into $\gamma_{\mathrm{a}}$ and $\gamma_{\mathrm{p}}$ as a function of $\mathrm{p}_{\mathrm{H}_{2} \mathrm{O}}$ 18 reveals that $\gamma_{p}$ depends indirectly on the metal film yield stress, which decreases with film thickness $h_{C u}$ 19 and temperature $\mathrm{T}$. There is negligible $\mathrm{Cu}$ plasticity observed only for $\mathrm{h}_{\mathrm{Cu}}=12 \mathrm{~nm}$, where the yield 20 strength is high enough to prevent $\gamma_{a}$ from activating plasticity. The temperature-induced yield stress 21 reduction increases $\gamma_{p}$, which offsets the decrease in $\gamma_{a}$ due to water-induced siloxane bond weakening, 22 leading to a net increase in $\Gamma_{\mathrm{FT}}$ with temperature. At high $\mathrm{p}_{\mathrm{H}_{2} \mathrm{O}}, \Gamma_{\mathrm{FT}}$ is limited by low bond strength $\gamma_{\mathrm{a}}$, 23 while plasticity dominates at low $\mathrm{p}_{\mathrm{H}_{2} \mathrm{O}}$. Our findings on the fracture behavior of molecularly modified 
1 metal-ceramic interfaces should be important for designing heterointerfaces for applications involving

2 exposures to thermo-mechano-chemical stresses.

3 We measured $\Gamma_{\mathrm{FT}}$ from four-point bending tests carried out at different water partial pressure between

$40.158 \mathrm{kPa} \leq \mathrm{p}_{\mathrm{H}_{2} \mathrm{O}} \leq 40.6 \mathrm{kPa}$ in the $278 \mathrm{~K} \leq \mathrm{T} \leq 358 \mathrm{~K}$ range on rectangular beams of dummy-

$5 \mathrm{Si} /$ epoxy/Ta/Cu$/ \mathrm{NML} / \mathrm{SiO}_{2} / \mathrm{Si}(001)$ structures. We note that, in our experiments, $\mathrm{p}_{\mathrm{H}_{2} \mathrm{O}}>2.3 \mathrm{kPa}$ is only

6 accessible above $298 \mathrm{~K}$ due to limitations of the humidity chamber. The test structures were fabricated

7 using procedures described in detail elsewhere[12]. Briefly, we used molecular self-assembly to deposit

8 NMLs of mercapto-propyl-tri-methoxysilane on surfaces of 85-nm-thick thermally grown silica films on

$9 \mathrm{Si}(001)$ substrates. The substrates were dipped in a $5 \mathrm{mM}$ solution of the organosilane in toluene for 30

10 minutes at $25{ }^{\circ} \mathrm{C}$. $\mathrm{Cu}$ films of different pre-chosen thicknesses in the $12 \mathrm{~nm} \leq \mathrm{h}_{\mathrm{Cu}} \leq 340 \mathrm{~nm}$ range were

11 sputter-deposited using a 7 mTorr Ar plasma in a $5 \times 10^{-7}$ Torr base pressure CVC tool. A 150 -nm-thick

12 Ta layer was deposited in vacuo on the $\mathrm{Cu}$ to circumvent poor $\mathrm{Cu}$-epoxy bonding via epoxy-Ta bonds

13 used to glue to a dummy $\mathrm{Si}$ wafer. The $\mathrm{Ta} / \mathrm{Cu} / \mathrm{NML} / \mathrm{SiO}_{2} / \mathrm{Si}(001)$ stacks were annealed at $300{ }^{\circ} \mathrm{C}$ in $2 \mathrm{x}$

$1410^{-7}$ Torr vacuum for 30 minutes prior to gluing them to dummy Si wafers using an epoxy. The dummy-

$15 \mathrm{Si} /$ epoxy/Ta/Cu/NML/SiO $/ 2 / \mathrm{Si}(001)$ structures were sliced into $5 \mathrm{~mm}$ x $40 \mathrm{~mm}$ beams for four-point bend

16 tests. A 0.13 -mm-wide notch was scribed on the host $\mathrm{Si}(001)$ wafer for crack initiation.

17 The dummy-Si/epoxy/Ta/Cu/NML/SiO $/ 2 / \mathrm{Si}(001)$ structures were subject to four-point bending at a

18 constant $10 \mathrm{~nm} / \mathrm{s}$ displacement rate in a Cincinnati Sub-Zero ZP-8 chamber that allows independent

19 control of relative humidity and temperature. The first load-displacement plateau at a critical driving

20 energy $\Gamma_{\mathrm{c}}$ corresponds to the crack reaching the weakest interface.[13] Relaxing the load by arresting the

21 external displacement at the plateau results in sub-critical interfacial delamination at monotonically

22 decreasing velocities. The delamination velocity $\mathrm{v}$ approaches zero as the driving energy $\Gamma$ diminishes to

23 a threshold fracture energy $\Gamma_{\mathrm{FT}}$. This corresponds to the free energy of hydrolysis of siloxane bridges at

24 the NML-silica interface, as indicated by fracture surface analyses by X-ray photoelectron

25 spectroscopy $[9,10]$. 
Our results show that the threshold fracture energy $\Gamma_{\mathrm{FT}}$ is a strong function of $\mathrm{p}_{\mathrm{H}_{2} \mathrm{O}}$, temperature and

2 the copper film thickness $\mathrm{h}_{\mathrm{Cu}}$. We first describe the role of $\mathrm{p}_{\mathrm{H}_{2} \mathrm{O}}$ for structures with $12 \mathrm{~nm} \leq \mathrm{h}_{\mathrm{Cu}} \leq 340 \mathrm{~nm}$

3 at $\mathrm{T}=298 \mathrm{~K}$ (see Figure 1a), where decreasing $\mathrm{p}_{\mathrm{H}_{2} \mathrm{O}}$ from $2.22 \mathrm{kPa}$ to $0.634 \mathrm{kPa}$ increases $\Gamma_{\mathrm{FT}}$ at all $\mathrm{h}_{\mathrm{Cu}}$.

4 The inverse linear correlation between $\Gamma_{\mathrm{FT}}$ and $\log _{\mathrm{e}} \mathrm{p}_{\mathrm{H}_{2} \mathrm{O}}$ is attributable to water-induced siloxane bridge

5 scission via hydrolysis at the NML-silica interface by $\mathrm{Si}-\mathrm{O}-\mathrm{Si}+\mathrm{H}_{2} \mathrm{O} \rightarrow 2 \mathrm{Si}-\mathrm{OH}$, similar to stress

6 corrosion cracking in glass[14].

$7 \quad$ From Figure $1 \mathrm{~b}$ we determine that the plastic energy $\gamma_{\mathrm{p}}$ is negligible for $\mathrm{h}_{\mathrm{Cu}}=12 \mathrm{~nm}$, by fitting the 8 interfacial work of adhesion purely as a function of the hydrolysis driving force and interfacial $\mathrm{Si}-\mathrm{O}-\mathrm{Si}$

9 bond density $\mathrm{N}_{\mathrm{Si}-\mathrm{O}-\mathrm{Si}} \mathrm{using}$

$$
\gamma_{\mathrm{a}}=\gamma_{0}-\mathrm{N}_{\mathrm{Si}-\mathrm{O}-\mathrm{Si}} \mathrm{kT} \log _{\mathrm{e}} \mathrm{p}_{\mathrm{H}_{2} \mathrm{O}}(1)
$$

11 We find that $\mathrm{N}_{\mathrm{Si}-\mathrm{O}-\mathrm{Si}}=1.4 \times 10^{20} \mathrm{~m}^{-2}$, which agrees well with $\mathrm{N}_{\mathrm{Si}-\mathrm{O}-\mathrm{Si}}=7.0 \times 10^{19} \mathrm{~m}^{-2}$ obtained by fitting 12 the $\mathrm{v}-\Gamma$ characteristics for different $\mathrm{p}_{\mathrm{H}_{2} \mathrm{O}}$ to a reaction-rate kinetics model for water-induced fracture in 13 orthosilicates[15,16]. In systems where plasticity is significant, the $\mathrm{N}_{\mathrm{Si}-\mathrm{O}-\mathrm{Si}}$ values determined by the two 14 methods can differ by more than two orders of magnitude[17,18], which is clearly not the case here. 15 Hence, we conclude that $\Gamma_{\mathrm{FT}}=\gamma_{\mathrm{a}}$, which is only a function of $\mathrm{p}_{\mathrm{H}_{2} \mathrm{O}}$. Thus, $\Gamma_{\mathrm{FT}}$ is tantamount to the product 16 of the $\mathrm{N}_{\mathrm{Si}-\mathrm{O}-\mathrm{Si}}$ and the free energy of siloxane hydrolysis $\Delta \mathrm{G}_{\mathrm{Si}-\mathrm{O}-\mathrm{Si}}$ for our interfaces with $\mathrm{h}_{\mathrm{Cu}}=12 \mathrm{~nm}$. 17 Using the $\mathrm{N}_{\mathrm{Si}-\mathrm{O}-\mathrm{Si}}$ values, we estimate the NML-tailored interface fracture energy to be in $1.07 \mathrm{~J} / \mathrm{m}^{2} \leq \Gamma_{\mathrm{FT}}$ $18 \leq 1.79 \mathrm{~J} / \mathrm{m}^{2}$ range, which corresponds to the $48 \leq \Delta \mathrm{G}_{\mathrm{Si}-\mathrm{O}-\mathrm{Si}} \leq 80 \mathrm{meV} /$ bond. These values are typical of Si19 O-Si bonds in the presence of water,[19] which is higher than van der Waals bonding strength (4.1-41 $20 \mathrm{meV} /$ bond[20]) and similar to weak hydrogen bonding strength (41-410 meV/bond[20]). This result 21 suggests that the weak Si-O-Si bonding precludes plasticity for $\mathrm{h}_{\mathrm{Cu}}=12 \mathrm{~nm}$.

22 For $\mathrm{h}_{\mathrm{Cu}}=35 \mathrm{~nm}$, we observe two regimes in the $0.634 \mathrm{kPa} \leq \mathrm{p}_{\mathrm{H}_{2} \mathrm{O}} \leq 2.22 \mathrm{kPa}$ range at $298 \mathrm{~K}$ (Figure 23 1b). For kTlog $\mathrm{p}_{\mathrm{H}_{2} \mathrm{O}} \geq 6.1 \mathrm{meV}, \Gamma_{\mathrm{FT}}$ decreases linearly by $0.5 \mathrm{Jm}^{-2}$ as $\mathrm{kTlog} \mathrm{e}_{\mathrm{H}_{2} \mathrm{O}}$ increases up to $20 \mathrm{meV}$, 24 reminiscent of the free energy dependence[15] of an equilibrium reaction. We attribute the linear 
1 behavior[9] in regime I at high $\mathrm{p}_{\mathrm{H}_{2} \mathrm{O}}$ to the $\gamma_{\mathrm{a}}$ increase with decreasing water chemical potential, as seen

2 for $\mathrm{h}_{\mathrm{Cu}}=12 \mathrm{~nm}$. If we assume that only $\gamma_{\mathrm{a}}$ changes, from Eq. 1 we obtain $\mathrm{N}_{\mathrm{Si}-\mathrm{O}-\mathrm{Si}}=2.72 \times 10^{20} \mathrm{~m}^{-2}$ for

$3 \mathrm{kTlog}_{\mathrm{e}} \mathrm{p}_{\mathrm{H}_{2} \mathrm{O}} \geq 6.1 \mathrm{meV}$, and $\mathrm{N}_{\mathrm{Si}-\mathrm{O}-\mathrm{Si}}=4.93 \times 10^{20} \mathrm{~m}^{-2}$ for $\mathrm{kTlog}_{\mathrm{e}} \mathrm{p}_{\mathrm{H}_{2} \mathrm{O}} \leq 6.1 \mathrm{meV}$. In regime II, the $\mathrm{N}_{\text {Si-O-Si }}$

4 values are two- to three-fold higher than that seen for $\mathrm{h}_{\mathrm{Cu}}=12 \mathrm{~nm}$. This indicates that besides $\gamma_{\mathrm{a}}$, which is

5 independent of $\mathrm{h}_{\mathrm{Cu}}, \Gamma_{\mathrm{FT}}$ for $\mathrm{h}_{\mathrm{Cu}}=35 \mathrm{~nm}$ includes metal film plasticity[9,17-18] that is sensitive directly to

$6 \mathrm{~h}_{\mathrm{Cu}}$ and indirectly to $\mathrm{p}_{\mathrm{H}_{2} \mathrm{O}}$. Indeed, the interface fracture energy $\Gamma_{\mathrm{FT}} \sim 2 \mathrm{Jm}^{-2}$ at $\mathrm{kTlog}_{\mathrm{e}} \mathrm{p}_{\mathrm{H}_{2} \mathrm{O}} \sim 6.1 \mathrm{meV}$ for

$7 \mathrm{~h}_{\mathrm{Cu}}=35 \mathrm{~nm}$ corresponds to a film stress of $\sigma_{\text {film }} \sim 2.9 \mathrm{GPa},[9]$ which is within $15 \%$ to $32 \%$ of the $\mathrm{Cu}$ film

8 yield stress $\sigma_{\mathrm{y}}$ determined from nanoindentation measurements on blanket films[9] and molecular

9 dynamics simulations[21].

10 For $\mathrm{h}_{\mathrm{Cu}}>35 \mathrm{~nm}$ (Fig. 1) plasticity is expected to set in at lower fracture energies (higher $\mathrm{p}_{\mathrm{H}_{2} \mathrm{O}}$ ) because

11 of the lower yield stress in thicker films. We are unable to capture this transition for $\mathrm{h}_{\mathrm{Cu}}>35 \mathrm{~nm}$ in Figure

121 because of a $20 \mathrm{meV}$ cap in the water chemical potential at room temperature in our humidity chamber

13 However, we show later below that the plasticity onset can be captured in thicker films (e.g., $\left.\mathrm{h}_{\mathrm{Cu}}=100 \mathrm{~nm}\right)$

14 at higher temperatures (e.g., >323K) that allow access to higher water chemical potentials.

15 Based on $\gamma_{\mathrm{a}}$ for $\mathrm{h}_{\mathrm{Cu}}=12 \mathrm{~nm}$, we can estimate $\gamma_{\mathrm{p}}$ for thicker films (e.g., $\mathrm{h}_{\mathrm{Cu}}=35 \mathrm{~nm}$ ) by

$$
\gamma_{\mathrm{p}}=\Gamma_{\mathrm{FT}}-\gamma_{\mathrm{a} 12 \mathrm{~nm}}(2)
$$

17 where $\gamma_{\mathrm{a} 12 \mathrm{~nm}}$ is the adhesion energy for $\mathrm{h}_{\mathrm{Cu}}=12 \mathrm{~nm}$. Figure 2 plots the maximum plastic energy $\gamma_{\mathrm{p}-\max }$ 18 and minimum plastic energy $\gamma_{\mathrm{p}-\min }$ and the slope of $\mathrm{d} \Gamma_{\mathrm{FT}} / \mathrm{d} \log \mathrm{p}_{\mathrm{H}_{2} \mathrm{O}}$ for various $\mathrm{h}_{\mathrm{Cu}}$. The increase in $19 \mathrm{~d} \Gamma_{\mathrm{FT}} / \mathrm{dlog}_{\mathrm{e}} \mathrm{p}_{\mathrm{H}_{2} \mathrm{O}}$ with $\mathrm{h}_{\mathrm{Cu}}$ is consistent with theoretical predictions[2] for $\mathrm{Cu}$ films at high $\gamma_{\mathrm{a}}$. The difference 20 between the $\gamma_{\mathrm{p}-\max }$ and $\gamma_{\mathrm{p}-\min }$ at a given $\mathrm{h}_{\mathrm{Cu}}$ is attributable to the difference in $\gamma_{\mathrm{a}}$ due to $\mathrm{p}_{\mathrm{H}_{2} \mathrm{O}}$. Both $\gamma_{\mathrm{p}-\max }$ and

$21 \gamma_{\mathrm{p}-\mathrm{min}}$ increase with $\mathrm{h}_{\mathrm{Cu}}$ at all accessible $\mathrm{p}_{\mathrm{H}_{2} \mathrm{O}}$, but saturate for $\mathrm{h}_{\mathrm{Cu}}>165 \mathrm{~nm}$ (Figure 2). Even $\gamma_{\mathrm{p}-\min }{ }^{--}$ 22 measured at the highest $\mathrm{p}_{\mathrm{H}_{2} \mathrm{O}^{--}}$increases by more than an order of magnitude from $\gamma_{\mathrm{p}-\mathrm{min}}=0.4 \mathrm{Jm}^{-2}$ for $\mathrm{h}_{\mathrm{Cu}}$ $23=35 \mathrm{~nm}$ to $\gamma_{\mathrm{p}-\min }=6.1 \mathrm{Jm}^{-2}$ for $\mathrm{h}_{\mathrm{Cu}}=165 \mathrm{~nm}$. The linear increase in $\gamma_{\mathrm{p}-\max }$ and $\gamma_{\mathrm{p}-\min }$ is due to the 
expected[22-24] yield stress reduction with increasing film thickness up to $\mathrm{h}_{\mathrm{Cu}} \sim 165 \mathrm{~nm}$. Saturation in $\gamma_{\mathrm{p}}$

2 for $\mathrm{h}_{\mathrm{Cu}}>165 \mathrm{~nm}$ is indicative of a $\sigma_{\mathrm{y}}$ plateau above this thickness.

3 Nanoindentation measurements on $\mathrm{Cu}$ films[9] show that $\sigma_{\mathrm{y}}$ decreases rapidly with $\mathrm{h}_{\mathrm{Cu}}$ for $\mathrm{h}_{\mathrm{Cu}} \leq 165$

$4 \mathrm{~nm}$ (Figure 3a). Since plastic zone size[24] $\mathrm{R}_{0}$ can be related to $\sigma_{\mathrm{y}}$ through

$$
R_{0}=\frac{E \gamma_{a}}{3 \pi\left(1-v^{2}\right) \sigma_{y}^{2}},(3)
$$

where $E$ is the $\mathrm{Cu}$ stiffness and $v$ the Poisson's ratio, we find that for $\mathrm{h}_{\mathrm{Cu}}>75 \mathrm{~nm} \mathrm{R}_{0} \leq 4 \mathrm{~nm}$ calculated with $\gamma_{\mathrm{a}}=1.79 \mathrm{~J} \mathrm{~m}^{-2}$ at $\mathrm{p}_{\mathrm{H}_{2} \mathrm{O}}=0.634 \mathrm{kPa}$ while $\mathrm{R}_{0} \geq 1 \mathrm{~nm}$ calculated with $\gamma_{\mathrm{a}}=0.78 \mathrm{~J} \mathrm{~m}^{-2}$ at $\mathrm{p}_{\mathrm{H}_{2} \mathrm{O}}=2.2 \mathrm{kPa}$ (Figure 3a). Although $\mathrm{R}_{0}$ scales with $\mathrm{h}_{\mathrm{Cu}}$, our results showing that $\mathrm{R}_{0}<<\mathrm{h}_{\mathrm{Cu}}$ suggests that plasticity is localized near the interfacial crack tip where debonding occurs. Examining the variations of $\gamma_{\mathrm{p}}$ (Figure 2) and $R_{0}$ (Figure 3a) with respect to $h_{C u}$, we find that $\gamma_{p}$ scales linearly with $R_{0}$ (Figure $3 b$ ) as expected for 11 small-scale yielding[25]. This trend is consistent with our observation of $\gamma_{\mathrm{p}}=0$ for $\mathrm{h}_{\mathrm{Cu}} \leq 12 \mathrm{~nm}$ due to high $\sigma_{\mathrm{y}}$ in thinner films.

In order to assess temperature and moisture effects, we measured the interfacial fracture energy $\Gamma_{\mathrm{FT}}$ of 14 structures with a fixed $\mathrm{h}_{\mathrm{Cu}}=100 \mathrm{~nm}$ for $278 \mathrm{~K} \leq \mathrm{T} \leq 358 \mathrm{~K}$ and $0.158 \mathrm{kPa} \leq \mathrm{p}_{\mathrm{H}_{2} \mathrm{O}} \leq 40.6 \mathrm{kPa}$. For a constant $\mathrm{p}_{\mathrm{H}_{2}} \mathrm{O}, \Gamma_{\mathrm{FT}}$ increases with temperature (Figure 4). This overall trend is attributable to increased $\gamma_{\mathrm{p}}$ due to temperature-induced reduction in yield stress[26] despite any decreases in $\gamma_{\mathrm{a}}$. At temperatures $>300$ $\mathrm{K}$, we observe two different rates of $\Gamma_{\mathrm{FT}}$ increase as $\mathrm{p}_{\mathrm{H}_{2} \mathrm{O}}$ decreases. At high $\mathrm{p}_{\mathrm{H}_{2} \mathrm{O}}$ (regime $\mathrm{I}$ ) at a given temperature, the rate of $\Gamma_{\mathrm{FT}}$ increase is small, which is consistent with limited localized crack tip plasticity 19 expected at low $\gamma_{\mathrm{a}}$. Decreasing $\mathrm{p}_{\mathrm{H}_{2} \mathrm{O}}$ increases $\gamma_{\mathrm{a}}$ due to diminution of moisture-induced siloxane bond weakening and scission[10]. The increased $\gamma_{\mathrm{a}}$ at lower $\mathrm{p}_{\mathrm{H}_{2} \mathrm{O}}$ supports a much higher $\gamma_{\mathrm{p}}$, leading to a higher

$21 \Gamma_{\mathrm{FT}}$ (regime II). We do not observe the bond-breaking regime I for thicker films at $\mathrm{T}<323 \mathrm{~K}$ because 22 water chemical potentials above $20 \mathrm{meV}$ are inaccessible in our experiments at these temperatures. This 23 single regime of plasticity is analogous to linear increase in plasticity with increasing $\mathrm{h}_{\mathrm{Cu}}$ due to $\sigma_{\mathrm{y}}$ 
1 reduction with $\mathrm{Cu}$ film thickness, described earlier. Collectively, these results thus indicate that the

2 temperature-induced yield stress decrease significantly increases $\gamma_{\mathrm{p}}$, offsetting any decreases in $\gamma_{\mathrm{a}}$.

3 In summary, we have investigated the effects of moisture and temperature on the work of adhesion

4 and metal plasticity for a metal-dielectric heterointerface modified with a nanomolecular layer. Our

5 results indicate that copper film yielding occurs only above a critical film thickness. While humidity

6 decreases the work of adhesion and the fracture energy at all thicknesses, increasing the temperature

7 increases the fracture energy by lowering the yield stress for films above a critical thickness. These

8 findings provide an atomistic understanding of heterointerfacial fracture, which should be important for

9 designing heterointerfaces for applications involving exposures to thermo-mechano-chemical stresses.

10 This work was supported by the National Science Foundation grant CMMI 1100933/926.

\section{References}

12 [1] M.J. Cordill, N.R. Moody, D.F. Bahr, Acta Mater. 53 (2005) 2555-2562.

13 [2] M. Lane, R.H. Dauskardt, A. Vainchtein, H. Gao, J. Mater. Res. 15 (2000) 2758-2769.

14 [3] C.S. Litteken, S. Strohband, R.H. Dauskardt, Acta Mater. 53 (2005) 1955-1961.

15 [4] J. Lankford, D.L. Davidson, K.S. Chan, Metall. Trans. A 15 (1984) 1579-1588.

16 [5] A.A. Griffith, Philos. Trans. R. Soc. A Math. Phys. Eng. Sci. 221 (1921) 163-198.

17 [6] G.R. Irwin, Fracture Dynamics: Fracturing of Metals, American Society for Metals, Cleveland, $18 \quad \mathrm{OH}, 1948$.

19 [7] J.W. Hutchinson, J. Mech. Phys. Solids 16 (1968) 13-31.

20 [8] A.. Volinsky, N.. Moody, W.. Gerberich, Acta Mater. 50 (2002) 441-466.

21 [9] A. Jain, B. Singh, S. Garg, N. Ravishankar, M. Lane, G. Ramanath, Phys. Rev. B 83 (2011) 22035412.

23 [10] D.D. Gandhi, M. Lane, Y. Zhou, A.P. Singh, S. Nayak, U. Tisch, M. Eizenberg, G. Ramanath, Nature 447 (2007) 299-302.

[11] G. Ramanath, G. Cui, P.G. Ganesan, X. Guo, a. V. Ellis, M. Stukowski, K. Vijayamohanan, P. Doppelt, M. Lane, Appl. Phys. Lett. 83 (2003) 383.

[12] S. Garg, B. Singh, X. Liu, A. Jain, N. Ravishankar, L. Interrante, G. Ramanath, J. Phys. Chem. Lett. 1 (2010) 336-340.

29 [13] Q. Ma, J. Mater. Res. 12 (1997) 840-845. 
1 [14] J.J. Vlassak, Y. Lin, T.Y. Tsui, Mater. Sci. Eng. A 391 (2005) 159-174.

2 [15] M. Lane, Annu. Rev. Mater. Res. 33 (2003) 29-54.

3 [16] R.F. Cook, E.G. Liniger, J. Am. Ceram. Soc. 76 (1993) 1096-1105.

4 [17] B.R. Lawn, Fracture of Brittle Solids, Cambridge University Press, 1993.

$5 \quad$ [18] F.W. Zeng, S.M. Gates, M.W. Lane, AIP Adv. 4 (2014) 057112.

6 [19] A. Pelmenschikov, H. Strandh, L.G.M. Pettersson, J. Leszczynski, J. Phys. Chem. B 104 (2000) 7 5779-5783.

8 [20] R. Chang, J.W.J. Thoman, Physical Chemistry for the Chemical Sciences, University Science 9 Books, 2014.

10 [21] J. Schiøtz, K.W. Jacobsen, Science 301 (2003) 1357-9.

11 [22] V. Tvergaard, J.W. Hutchinson, Philos. Mag. A 70 (1994) 641-656.

12 [23] N.I. Tymiak, A.A. Volinsky, M.D. Kriese, S.A. Downs, W.W. Gerberich, Metall. Mater. Trans. A $13 \quad 31(2000) 863-872$.

14 [24] M.W. Lane, J.M. Snodgrass, R.H. Dauskardt, Microelectron. Reliab. 41 (2001) 1615-1624.

15 [25] M. Lane, R.H. Dauskardt, N. Krishna, I. Hashim, J. Mater. Res. 15 (2000) 203-211.

16 [26] R.-M. Keller, S.P. Baker, E. Arzt, Acta Mater. 47 (1999) 415-426.

17

18

19 


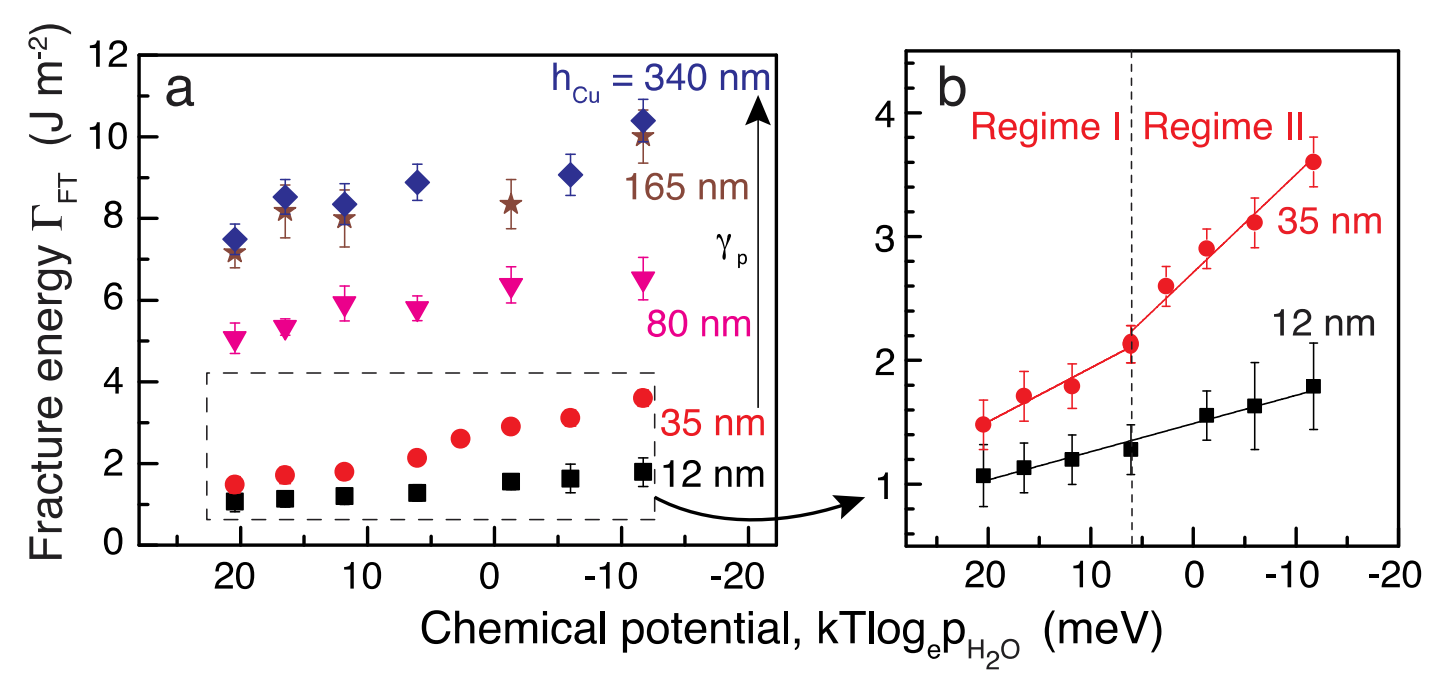

$412 \mathrm{~nm} \leq \mathrm{h}_{\mathrm{Cu}} \leq 340 \mathrm{~nm}$ and $(\mathrm{b}) \mathrm{h}_{\mathrm{Cu}}=12 \mathrm{~nm}$ and $\mathrm{h}_{\mathrm{Cu}}=35 \mathrm{~nm}$. 


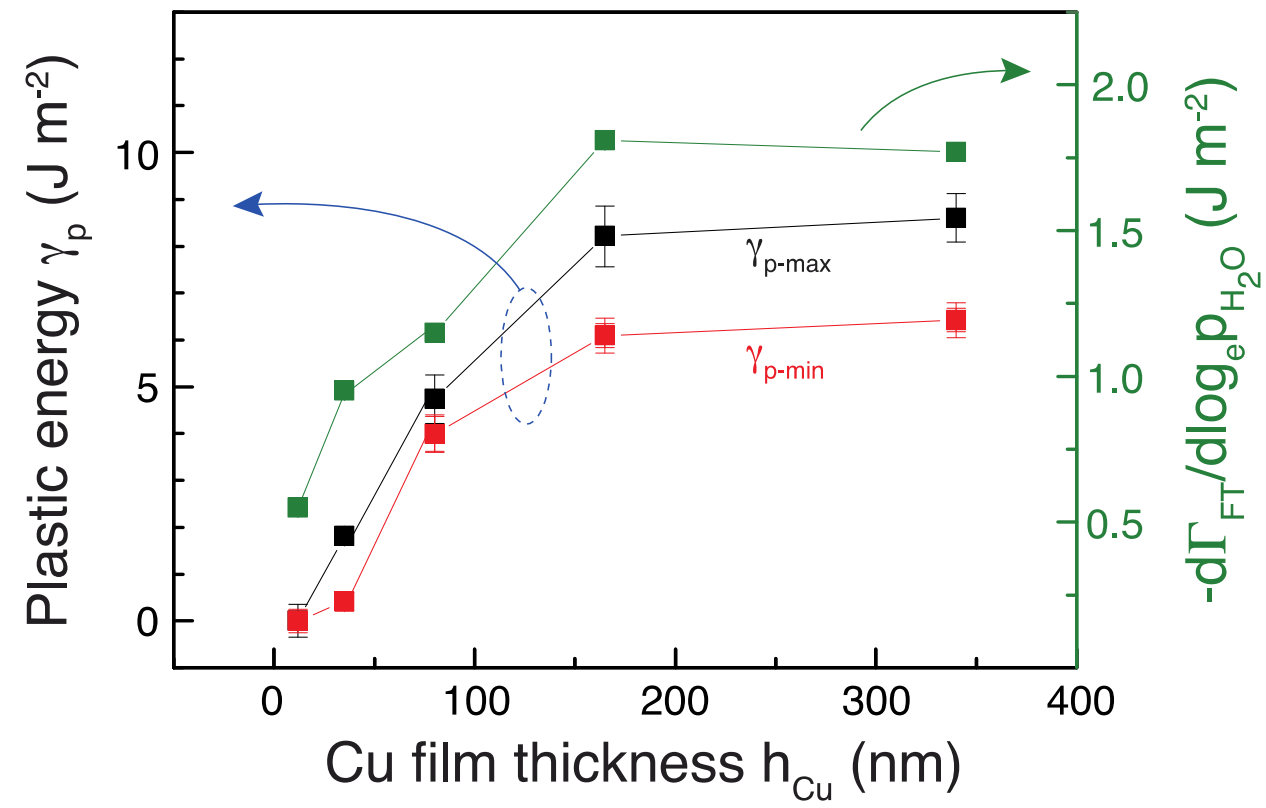

4 Figure 2. Plots capturing the effects of $\mathrm{h}_{\mathrm{Cu}}$ on the minimum plasticity $\gamma_{\mathrm{p}-\mathrm{min}}$ at $\mathrm{p}_{\mathrm{H}_{2} \mathrm{O}}=2.22 \mathrm{kPa}$ and maximum plasticity $\gamma_{\mathrm{p}-\max }$ at $\mathrm{p}_{\mathrm{H}_{2} \mathrm{O}}=0.633 \mathrm{kPa}$, and the rate of increase of fracture energy $\Gamma_{\mathrm{FT}}$ with respect to the natural logarithm of water partial pressure. 

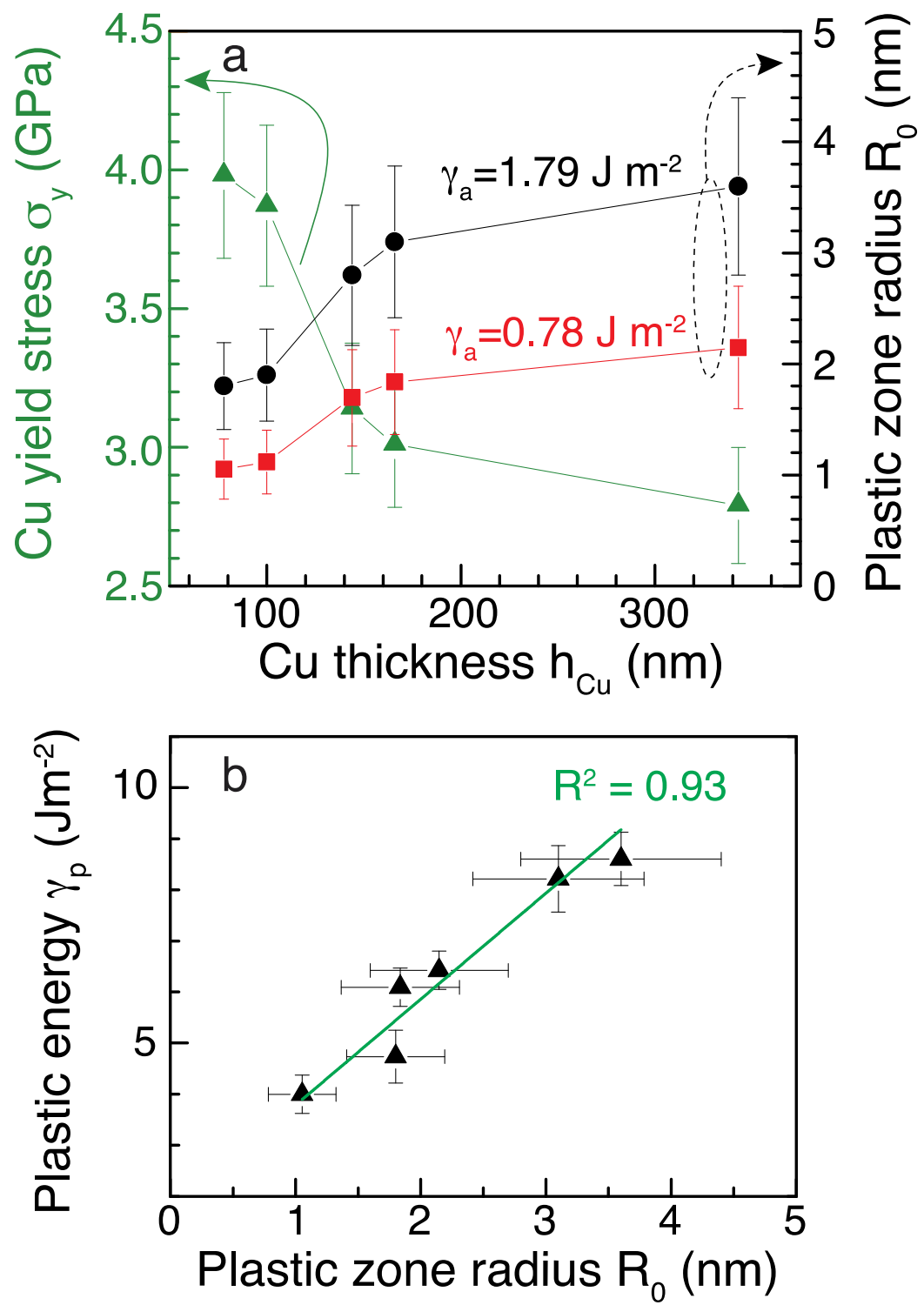

4 Figure 3. (a) Plastic zone radius (open symbols) and yield stress (closed triangle) calculated from the

5 adhesive strength $\gamma_{\mathrm{a}}$ at $\mathrm{p}_{\mathrm{H}_{2} \mathrm{O}}=0.633 \mathrm{kPa}$ (circles) and at $\mathrm{p}_{\mathrm{H}_{2} \mathrm{O}}=2.22 \mathrm{kPa}$ (squares) and nanoindentation

6 measurements on $\mathrm{Cu}$ films with $\mathrm{h}_{\mathrm{Cu}}>75 \mathrm{~nm}$. (b) Linear relationship between calculated plastic zone

7 radius and interface plastic energy, yields a slope of $2.07 \mathrm{GPa}$. 


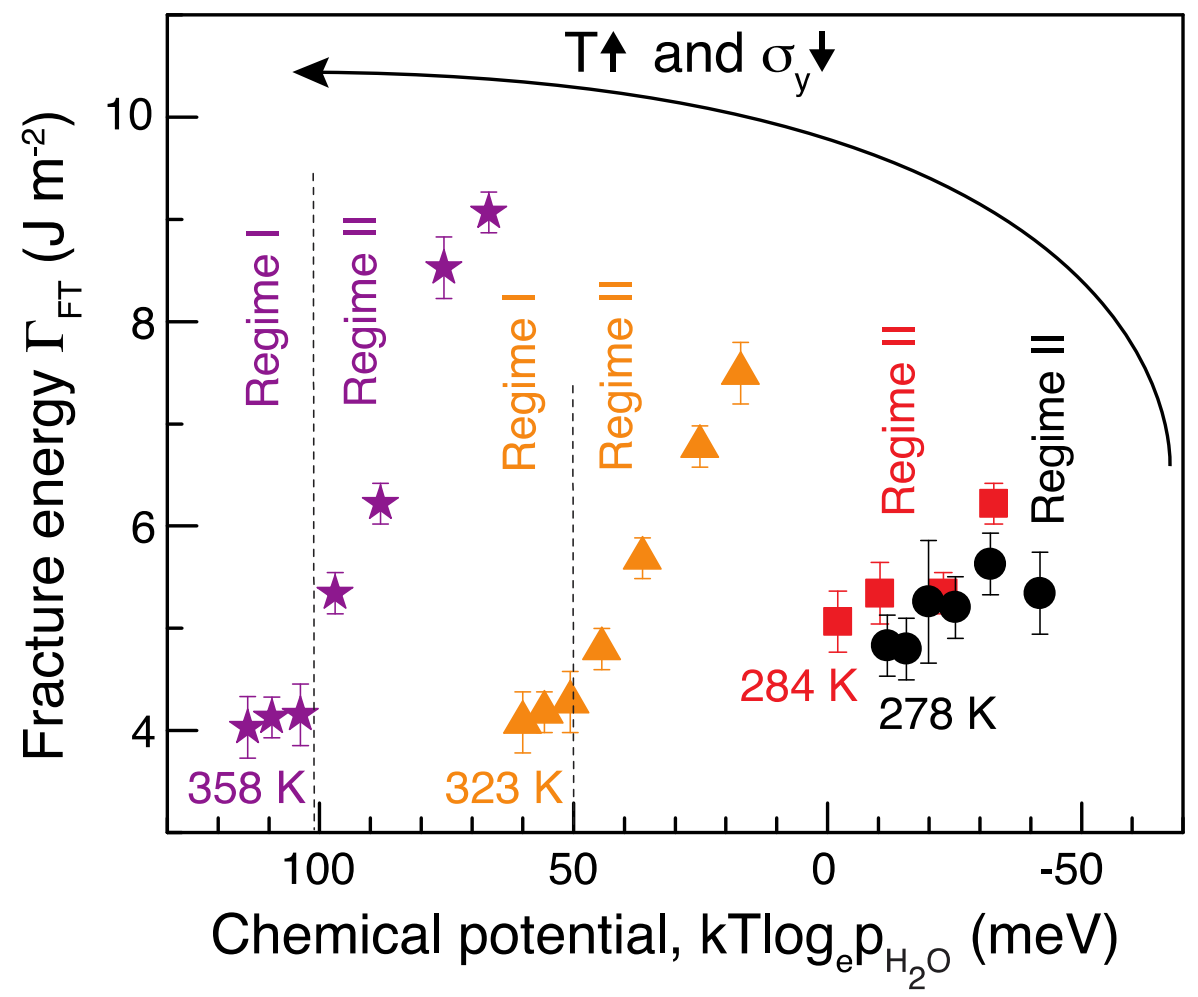

Figure 4. Fracture energy of $\mathrm{Cu} / \mathrm{NML} /$ silica interfaces obtained as a function of chemical potential at different temperatures and water partial pressures for structures with $\mathrm{h}_{\mathrm{Cu}}=100 \mathrm{~nm}$. Two regimes are seen at $358 \mathrm{~K}$ (stars) and 323 (triangles), while at $284 \mathrm{~K}$ (squares) and $278 \mathrm{~K}$ (circles) only the second regime is seen. 


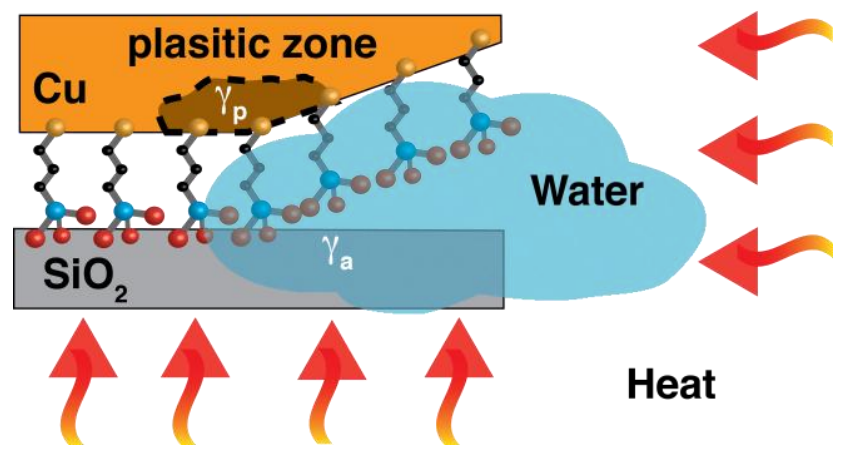

Graphical Abstract 